\title{
Surgical strategy for the bicuspid aortic valve: Tricuspidization with cusp extension versus pulmonary autograft
}

David Michael McMullan, MD, ${ }^{\mathrm{c}}$ Guido Oppido, MD, ${ }^{\mathrm{a}}$ Ben Davies, MD, ${ }^{\text {a }}$ Yoichi Kawahira, MD, ${ }^{\mathrm{a}}$ Andrew Donald Cochrane, MD, ${ }^{a, b}$ Yves d'Udekem d'Acoz, MD, ${ }^{a, b}$ Daniel J. Penny, MD, a,d and Christian P. Brizard, MD ${ }^{a, b}$

From the Cardiac Surgery Unit, The Royal Children's Hospital, Parkville, Victoria, Australia'; the Department of Pediatrics, The University of Melbourne, Melbourne, Victoria, Australiab; Cardiovascular Surgery, Children's National Medical Center, Washington, $\mathrm{DC}^{\mathrm{c}}$; and the Cardiology Department, The Royal Children's Hospital, Parkville, Victoria, Australia.

Read at the Eighty-sixth Annual Meeting of The American Association for Thoracic Surgery, Philadelphia, Pa, April 29-May 3, 2006.

Received for publication May 4, 2006; revisions received Jan 2, 2007; accepted for publication Jan 8, 2007.

Address for reprints: Christian Pierre Robert Brizard, MD, Cardiac Surgery Unit, The Royal Children's Hospital, Flemington Rd, Parkville, Victoria, 3052, Australia (E-mail: christian.brizard@rch.org.au).

J Thorac Cardiovasc Surg 2007;134:90-8

$0022-5223 / \$ 32.00$

Copyright (๑) 2007 by The American Association for Thoracic Surgery

doi:10.1016/j.jtcvs.2007.01.054
Objective: The congenitally bicuspid aortic valve is the most common etiologic factor associated with clinically significant aortic stenosis and/or regurgitation in pediatric patients. Beyond infancy, surgical intervention typically involves valve repair with cusp thinning and commissurotomy or valve replacement, primarily with pulmonary autograft in the current era. An aortic valve repair technique using tricuspidization with cusp extension was introduced in 1999. This study compares the midterm clinical outcome in patients undergoing valve repair by tricuspidization with cusp extension with those receiving a pulmonary autograft (Ross).

Methods: A retrospective study was performed on all consecutive patients with symptomatic bicuspid aortic valve disease who underwent tricuspidization with cusp extension or a Ross procedure between 1999 and 2005. In both groups, all patients were at least 1 year of age at time of the operation.

Results: During this period, 21 children (median age 12.6 years, range $2.6-18$ years) underwent tricuspidization with cusp extension (TCE group) and 25 children (median age 10.2 years, range 11.5 months-20.1 years) underwent the Ross procedure. Prior balloon valvuloplasty was performed in $5(24 \%)$ of the children in the TCE group and 16 (64\%) of the children in the Ross group. Prior surgical commissurotomy was performed in 4 (19\%) TCE patients and in 9 (36\%) Ross patients. During a median follow-up period of 36.4 months (range 2.5 months-7.4 years), 2 (10\%) patients in the TCE group required valve-preserving early revision of the repair, 2 (10\%) TCE patients required subsequent aortic valve replacement at 16 and 33 months, 1 (4\%) Ross patient required subsequent valve repair at 5 years, and $1(4 \%)$ Ross patient underwent cardiac transplantation at 46 months. At 36 months, the actuarial freedom from reintervention on the aortic valve or autograft was $90 \%$ in the TCE group, with 11 patients at risk, and $100 \%$ in Ross patients, with 13 patients at risk $(P=.39)$; the freedom from moderate valve dysfunction or reintervention was $66 \%$ for TCE patients and $95 \%$ for Ross patients $(P=.07)$. There were no deaths, and all but 1 Ross patient remain in New York Heart Association class I.

Conclusions: Reintervention rates in patients undergoing tricuspidization with cusp extension or a primary Ross procedure are similar. Valve performance in the TCE group is satisfactory at midterm follow-up, but the Ross repair appears to provide greater stability of valve function. These results suggest that repair with valve tricuspidization and cusp extension provides reliable palliation of the symptomatic bicuspid aortic valve.

$\mathrm{P}$ resent in $1 \%$ to $2 \%$ of the population, the congenitally bicuspid aortic valve is the most common etiologic factor associated with clinically significant aortic valve stenosis in pediatric patients. ${ }^{1}$ Critical bicuspid aortic stenosis is typically treated by balloon valvuloplasty or surgical valvotomy in neonates and 


\section{Abbreviations and Acronyms \\ $\mathrm{CL}=$ confidence limits \\ $\mathrm{TCE}=$ tricuspidization with cusp extension}

infants. Beyond infancy, surgical interventions involve valve repair techniques or valve replacement, primarily using the pulmonary autograft (Ross procedure) in the current era. Although midterm results of the Ross procedure are encouraging, ${ }^{2-4}$ there is evidence of increased valve dysfunction related to abnormal growth of the autograft in younger patients. ${ }^{5,6}$ It has been reported that the pulmonary autograft is more prone to dysfunction in the setting of a predominantly regurgitant native aortic valve ${ }^{7}$ or significant size mismatch between the native valve and autograft. Additionally, it has been proposed that the presence of a native bicuspid aortic valve is an additional risk factor for pulmonary autograft dysfunction. ${ }^{8}$ Although early aortic valve repair is an attractive option in these patients, techniques that preserve bicuspid geometry are associated with increased risk of valve dysfunction and early valve replacement. ${ }^{9}$ The technique of bicuspid aortic valve repair by tricuspidization with cusp extension (TCE) was introduced in our unit in 1999. This study compares the midterm clinical outcome in children undergoing valve repair with TCE and those receiving a pulmonary autograft.

\section{Patients and Methods}

From February 1999 to October 2005, 46 children (median age 13.3 years, range 11.5 months-20.1 years) underwent surgical treatment of congenitally bicuspid aortic valve disease at our institution. Indications for surgery were severe regurgitation or mean gradient greater than $50 \mathrm{~mm} \mathrm{Hg}$ or a combination of mean gradient greater than $50 \mathrm{~mm} \mathrm{Hg}$ and moderate regurgitation.
TABLE 2. Comparison of the anatomy of patients undergoing valve repair or pulmonary autograft

\begin{tabular}{lcc}
\hline & TCE $(\mathbf{n}=\mathbf{2 1})$ & Ross $(\mathbf{n}=\mathbf{2 5})$ \\
\hline Thickened edges & $15(71 \%)$ & $4(16 \%)$ \\
Cusp dysplasia/thickening & $5(24 \%)$ & $14(56 \%)$ \\
Prominent raphe & $17(80 \%)$ & $21(84 \%)$ \\
Commissural fusion & $11(52 \%)$ & $11(44 \%)$ \\
Torn cusp & $4(19 \%)$ & $8(32 \%)$ \\
Cusp hypoplasia & $4(19 \%)$ & $1(4 \%)$ \\
Cusp calcification & $1(5 \%)$ & $4(16 \%)$ \\
Subaortic membrane & $2(10 \%)$ & $3(12 \%)$ \\
Vegetations & 0 & $3(12 \%)$ \\
\hline
\end{tabular}

TCE, Tricuspidization with cusp extension.

Twenty-one of these patients (mean age 12.6 years, range 2.6-18 years) underwent aortic valve TCE and 25 patients (mean age 10.2 years, range 11.5 months-20.1 years) underwent placement of a pulmonary autograft (Table 1). The primary indication for surgery was aortic insufficiency in 11 (52\%) TCE versus 5 (20\%) Ross $(P=.023)$, aortic stenosis in $1(5 \%)$ TCE versus $2(8 \%)$ Ross $(P=$ $.595)$, or combined aortic stenosis and insufficiency in $9(43 \%)$ TCE versus $18(72 \%)$ Ross patients $(P=.044)$. The median preoperative $\mathrm{z}$-value for the aortic valve annulus (at the nadir of the cusps) was +2.1 (range -0.3 to 9.2 ) in the TCE patients and +1.9 (range -4.4 to +8.7 ) in the Ross patients $(P=.165)$. Moderate or greater preoperative aortic insufficiency was present in $16(76.2 \%)$ TCE versus $21(84 \%)$ Ross patients $(P=.71)$, whereas moderate or greater aortic stenosis was present in 10 (48\%) TCE and $10(40 \%)$ Ross patients $(P=.766)$. Balloon valvuloplasty had been previously performed on 5 (24\%) TCE and $16(64 \%)$ Ross patients $(P=.007)$. Surgical commissurotomy had been performed on 4 (19\%) TCE patients and 9 (36\%) Ross patients $(P=.173)$. Two $(8 \%)$ Ross patients had previously undergone aortic valve repair. Precise anatomy and lesions are described in Table 2.

TABLE 1. Comparison of data for patients undergoing valve repair or pulmonary autograft

\begin{tabular}{lccc}
\hline & TCE $(\mathbf{n}=\mathbf{2 1})$ & Ross (n= 25) & P value \\
\hline Age $(\mathrm{y})$ & $12.6(2.6-18.0)$ & $10.2(1.0-20.1)$ & .157 \\
Weight $(\mathrm{kg})$ & $49.5(12.6-95.0)$ & $27.9(9.4-84.0)$ & .023 \\
Aortic annulus (mm) & $23(14-34)$ & $20(9-38)$ & .165 \\
Aortic annulus (z-value) & $2.1(-0.3-+9.2)$ & $1.9(-4.4-+8.7)$ & .165 \\
Indication for surgery & $11(52 \%)$ & $5(20 \%)$ & .023 \\
$\quad$ Aortic insufficiency & $1(5 \%)$ & $2(8 \%)$ & .595 \\
Aortic stenosis & $9(43 \%)$ & $18(72 \%)$ & .044 \\
Insufficiency and stenosis & $16(76 \%)$ & $21(84 \%)$ & .711 \\
$\geq$ Moderate insufficiency & $10(48 \%)$ & $10(40 \%)$ & .766 \\
$\geq$ Moderate stenosis & & $16(64 \%)$ & .007 \\
Prior interventions & $5(24 \%)$ & $9(36 \%)$ & .173 \\
Balloon valvuloplasty & $4(19 \%)$ & $2(8 \%)$ & \\
Surgical valvotomy & 0 & & \\
\hline
\end{tabular}

$T C E$, Tricuspidization with cusp extension. 


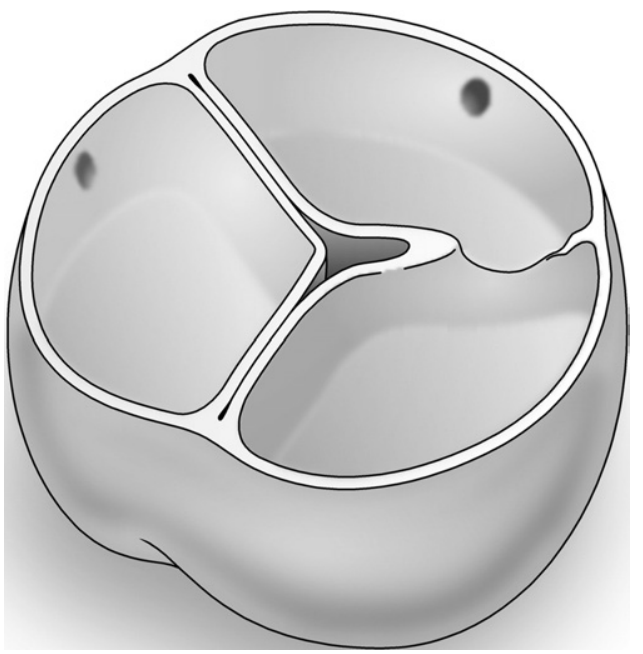

Figure 1. A raphe joining two congenitally fused cusps is a common element of the bicuspid aortic valve. Division of the raphe to the aortic wall creates three functionally independent cusps before pericardial leaflet extension. Source: Brizard C, d'Udekem Y, Alphoso N, Valvar disease in children. In: Yuh D, Vricella L, Baumgartner W, eds. The Johns Hopkins Manual of Cardiothoracic Surgery. New York, NY: The McGraw-Hill Companies; 2007. p. 1301-28. Reprinted with permission of the publisher.

\section{Choice of Procedure}

All patients were assessed by preoperative transthoracic echocardiography to study the structure and function of both the aortic and pulmonary valves. All patients were approved for TCE or Ross. Criteria for TCE included an aortic orifice that is equal to or greater than normal (normalized for body surface area) ${ }^{10,11}$ after commissurotomy and division of the raphe, adequate mobility of all cusps at the hinge point, absence of cusp dysplasia involving the belly of the cusps, commissures that are free of calcification or exuberant fibrosis, and normal location of the coronary ostia. When these criteria were met, TCE was the procedure of choice. When possible, we avoided the pulmonary autograft in the presence of pure aortic regurgitation or a significant aorta-pulmonary size mismatch. Rationale for repair was discussed with the family and the patient. Ross and mechanical prosthesis was presented as an option during the preoperative appointment. It was stated during this appointment that the durability of the repair is evaluated between 5 and 10 years.

\section{Surgical Technique}

$\boldsymbol{T C E}$. Through a full midline sternotomy, the anterior portion of the pericardium was exposed and carefully trimmed. A generous segment of pericardium was harvested before fixation in $0.625 \%$ glutaraldehyde for 8 minutes and rinsing. ${ }^{12,13}$ When possible, pericardium overlying the superior cavoatrial junction was preferentially used because it is characteristically thin and supple. ${ }^{14}$ Cardiopulmonary bypass was performed with bicaval and ascending aortic cannulation. The aortic valve was exposed by a high transverse aortotomy (at least $1 \mathrm{~cm}$ above the anterior commissure) with extension deep into the noncoronary sinus (hockey-stick incision). Cold blood car-

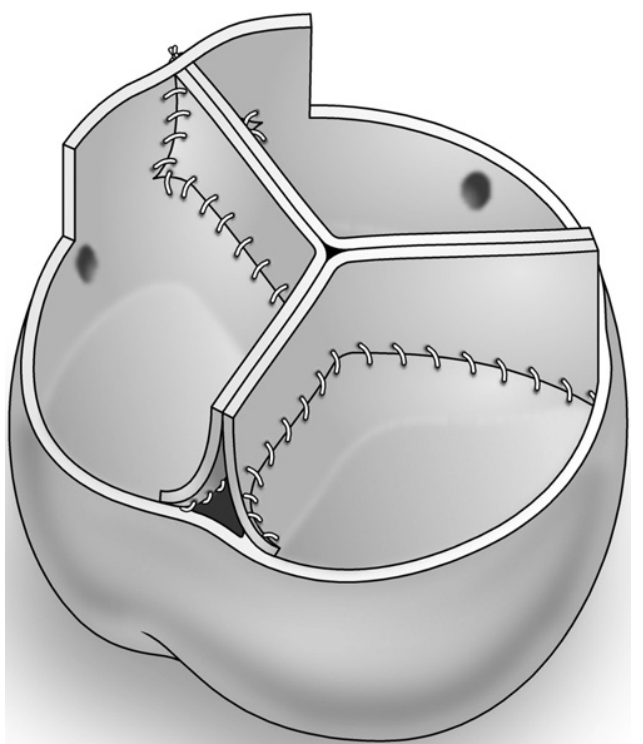

Figure 2. The height of coapting pericardial patches is increased toward the neocommissure to compensate for the lack of a true interleaflet triangle and to elevate the hinge point of the leaflets. Each new commissure is constructed by suturing the apposing short edges of each patch together and to the aortic wall, creating an elongated vertical axis of the native commissures. Source: Brizard C, d'Udekem Y, Alphoso N. Valvar disease in children. In: Yuh D, Vricella L, Baumgartner W, eds. The Johns Hopkins Manual of Cardiothoracic Surgery. New York, NY: The McGraw-Hill Companies; 2007. p. 1301-28. Reprinted with permission of the publisher.

dioplegic solution was given directly through the coronary ostia immediately after the aortotomy and then at 20-minute intervals. The cusps were then carefully examined and the annulus was measured with Hegar dilators. The raphe joining the congenitally fused cusps was divided to the aortic wall (Figure 1). When commissural fusion was present, commissurotomy was performed before determining the size of the annulus. Nodular irregularities along the surfaces of apposition of the cusps were removed.

Measurements of the length of the free edges of the three cusps were obtained and rectangular pieces of glutaraldehyde-treated pericardium were created. The height at the midportion of each pericardial extension was adjusted to the anatomy of each cusp and the underlying mechanism of valve dysfunction. Higher patches were used in the setting of very abnormal cusp tissue and significant cusp height discrepancy. In general, pericardial extensions were at least $5 \mathrm{~mm}$ and occasionally up to $7 \mathrm{~mm}$ in height. The height of coapting patches was increased toward the division of the raphe to compensate for the lack of a true interleaflet triangle and to elevate the hinge point of the cusps (Figure 2). The cusp extensions were sewn to the free edge of each cusp with running 6-0 polypropylene suture. Tissue gathering was used to correct the elongated free edges of the native cusps. A Frater ${ }^{15}$ stitch was used to join the three patches at the center of the valve to allow precise adjustment of any excessive length of patch. New commissures were constructed with a running suture apposing the short edges of 
two opposing patches together and to the aortic wall, creating an elongated vertical axis of the native commissures (Figure 2). The top part of this suture was reinforced with a single simple transfixing stitch. Intraoperative transesophageal echocardiography was used to assess aortic valve function after TCE repair. All patients undergoing TCE received intravenous heparin (10 units $\cdot \mathrm{kg}^{-1}$. $\mathrm{h}^{-1}$ for 72 hours) and daily aspirin for at least 6 months after the operation.

Ross. After determining that the aortic valve was not amenable to TCE repair, we harvested the pulmonary autograft. Then almost all infundibular muscle from the autograft was removed. The ascending aorta was divided and the coronary ostia were mobilized. Aortic valve cusps and associated dysplastic tissue were removed. When a small aortic annulus was present, an annulusenlarging procedure was performed. Three $(12 \%)$ patients underwent a Konno septoplasty with a Dacron septal patch and 5 (20\%) underwent a modified Konno septoplasty, involving direct anastomosis of the pulmonary autograft to the incised septum. The autograft was implanted as a mini-root, using running polypropylene suture reinforced with a strip of glutaraldehyde-treated pericardium or Teflon felt along the septum. The suture line was low in the left ventricular outflow tract, following a horizontal plane immediately below the nadir of the excised native aortic valve cusps. The coronary buttons were implanted into facing sinuses. Continuity between the autograft and ascending aorta was established at the level of the sinotubular junction with polypropylene suture. One patient underwent freehand implantation of the pulmonary autograft. The pulmonary outflow tract was reconstructed with either aortic or pulmonary homograft. Intraoperative transesophageal echocardiography was used to assess neoaortic valve and pulmonary homograft function.

\section{Follow-up}

All patients underwent transthoracic echocardiographic examination before hospital discharge and then usually at 6-month intervals unless a change in clinical examination or status was noted. Mean patient follow-up for the series was 36.4 months (range 2.5 months-7.4 years). Follow-up data were complete for all patients.

\section{Statistical Methods}

Statistical analysis was performed with Stata Version 8 software (StataCorp LP, College Station, Tex). Mean and sample proportions are expressed with $95 \%$ confidence limits (CL), using continuity correction for the upper and lower limits. Groups were compared by unpaired $t$ tests for continuous variables or Fisher exact tests for dichotomous variables. Survival analysis was performed by the Kaplan-Meier method and comparison of survival curves was performed by the log-rank test. Univariate analysis with logistic regression was used to test risk factors for failure. This study was done within the guidelines established by our institutional human research ethics committee.

\section{Results \\ TCE}

TCE was performed in all patients who fulfilled the selection criteria described in the "Patients and Methods" section. Two patients required early revision of the repair-
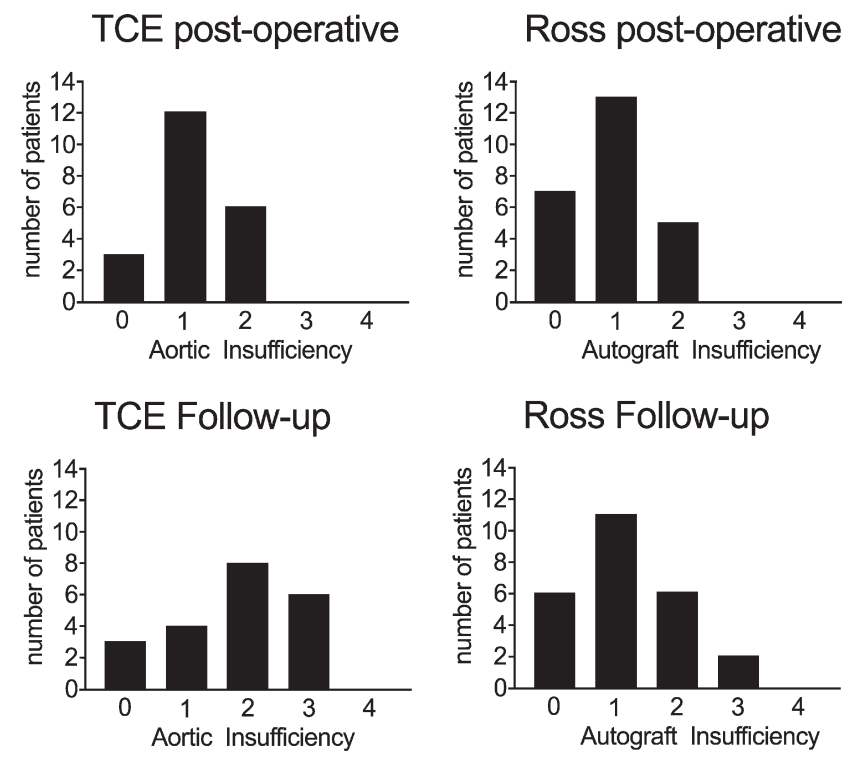

Figure 3. The degree of residual aortic regurgitation at the time of hospital discharge (upper panels) and at latest follow-up (lower pane/s) in patients undergoing tricuspidization with leaflet extension (TCE, left panels) and pulmonary autograft (Ross, right pane/s). TCE, Tricuspidization with cusp extension.

during the same operation for one and on the second postoperative day for the other. The native valve was preserved in both patients; one required pericardial extension replacement with higher patches, and the other needed a small triangular resection at the center of one of the patches. Postoperative echocardiography demonstrated a peak outflow tract gradient greater than $20 \mathrm{~mm} \mathrm{Hg}$ in 3 patients (22, 22, and $27 \mathrm{~mm} \mathrm{Hg}$ ). Residual aortic regurgitation at hospital discharge and at latest follow-up is presented in Figure 3. During a median follow-up of 34.7 months (range 8 months6.5 years), 1 patient underwent a Ross procedure for endocarditis 16 months after TCE and 1 patient required bioprosthetic aortic valve replacement for progressive aortic insufficiency 33 months after repair (9.5\%, CL: 0.1-32). In 4 patients a moderate aortic regurgitation was first diagnosed 9, 10, 31, and 40 months, respectively, after the TCE; severe regurgitation did not develop in any patient (Figure 3). At latest follow-up, the median peak instantaneous Doppler gradient was $20 \mathrm{~mm} \mathrm{Hg}$ (range 10-55 mm Hg) with 6 peak gradients greater than $20 \mathrm{~mm} \mathrm{Hg}(23 \mathrm{~mm} \mathrm{Hg}, \mathrm{n}=$ 3; $30 \mathrm{~mm} \mathrm{Hg}$ first noted at 38 months, $36 \mathrm{~mm} \mathrm{Hg}$ first noted at 26 months, and $55 \mathrm{~mm} \mathrm{Hg}$ first noted at 30 months). All patients are in New York Heart Association class I.

\section{Ross}

Of the 25 Ross patients, 9 had postoperative morbidity, including mediastinitis $(\mathrm{n}=1)$, complete atrioventricular block $(\mathrm{n}=$ 


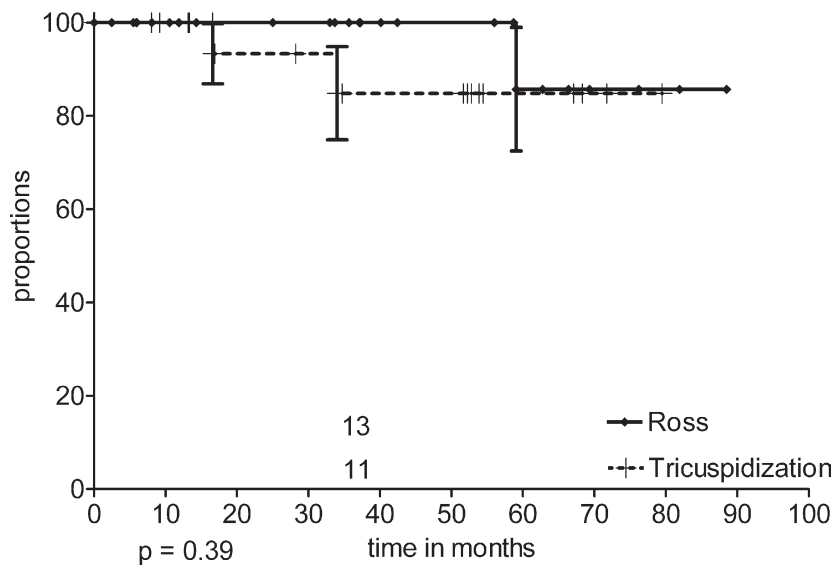

Figure 4. Kaplan-Meier curve comparing freedom from surgical reintervention on the aortic valve in patients undergoing pulmonary autograft (Ross, solid lines) and those undergoing tricuspidization with leaflet extension (TCE, dashed lines). Freedom from surgical reintervention at $\mathbf{3 6}$ months was $100 \%$ for Ross patients (13 patients at risk) and $\mathbf{9 0} \%$ for TCE patients (11 patients at risk) $(P=.39)$. TCE, Tricuspidization with cusp extension.

3 ), severe left ventricular dysfunction $(\mathrm{n}=1)$, right ventricular outflow tract stenosis requiring early reoperation $(\mathrm{n}=1)$, delayed sternal closure (1), bilateral sensoneuronal deafness ( $\mathrm{n}$ $=1$ ), and inferior myocardial infarction $(\mathrm{n}=1)$. Postoperative echocardiography demonstrated a peak outflow tract gradient greater than $20 \mathrm{~mm} \mathrm{Hg}$ in 1 patient. The degree of neoaortic regurgitation at hospital discharge and at latest follow-up is presented in Figure 3. During a median follow-up of 37.1 months (range 2.5 months-7.4 years), 1 patient required repair of the pulmonary autograft for severe regurgitation at 59 months, 1 patient was listed for transplantation at 33 months for severely restrictive left ventricular dysfunction and successfully underwent transplantation at 46 months, and 1 patient had early moderate regurgitation at 8 months (4\%, CL: 0-22.3). During the follow-up period, 2 patients had a mild gradient develop across the left ventricular outflow tract. At latest follow-up, the patient who underwent transplantation is in New York Heart Association class II and all others are in class I.

During this time, 2 (8\%, CL: 1.3-27) Ross patients required surgical or catheter-based intervention for right ventricle-pulmonary artery conduit failure.

\section{Statistical Analysis}

Two (10\%) TCE and 6 (25\%) Ross patients were free of aortic insufficiency $(P=.26)$ at latest follow-up. The degree of aortic regurgitation at discharge was similar between the two groups $(P=.06)$ but significantly different at latest follow-up $(P=.027)$. The degree of regurgitation increased significantly for the TCE patients $(P=.035)$, whereas it did not for the Ross patients $(P=.24)$. The actuarial freedom

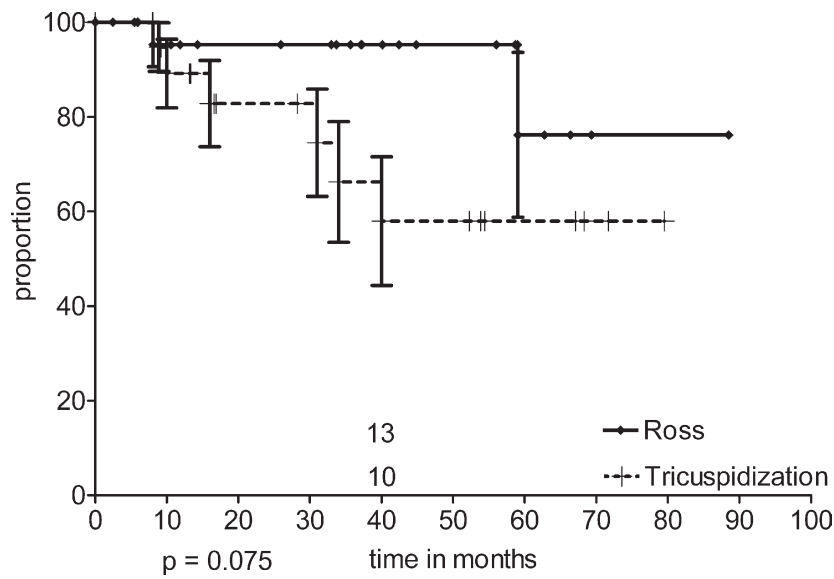

Figure 5. Kaplan-Meier curve comparing freedom from reoperation or the development of moderate or greater aortic regurgitation in patients undergoing pulmonary autograft (Ross, solid lines) and those undergoing tricuspidization with leaflet extension (TCE, dashed lines). Freedom from reoperation or moderate or greater aortic regurgitation at $\mathbf{3 6}$ months was $\mathbf{9 0 \%}$ for Ross patients (13 patients at risk) and $75 \%$ for TCE patients (10 patients at risk) ( $P$ $=.075)$. TCE, Tricuspidization with cusp extension.

from aortic valve reoperation was comparable between the two groups (log-rank test, $P=.39$ ) (Figure 4). The actuarial freedom from moderate or greater aortic regurgitation or reoperation (excluding right ventricular outflow tract procedures and cardiac transplantation) was also comparable between the two groups (log-rank test, $P=.075$ ) (Figure 5).

According to logistic regression, univariate analysis of age, sex, prior surgical intervention, prior surgical valvotomy, prior aortic balloon dilation, replacement of one whole cusp at surgery, grade of preoperative aortic regurgitation and preoperative mean instantaneous gradient failed to demonstrate predictive factors for TCE failure. However, there was a trend toward an association between younger age at the time of TCE and subsequent development of aortic regurgitation $(P=.06$ for patients younger than 100 months of age and $P=.02$ for patients younger than 10 years). No univariate analysis was performed for the Ross patients owing to the paucity of events.

Multivariate logistic regression was also performed with valve dysfunction or occurrence of reoperation as the dependent variable whereas the independent variables included the type of operation (TCE or Ross), age, body surface area, prior surgical intervention, mean valve gradient before, the dominant preoperative valve disease, and the grade of the preoperative valve regurgitation. There were no significant predictive variables.

Cox proportional analysis was performed, with time to reoperation used as the dependent variable. There were no significant predictive variables. 


\section{Discussion}

Introduced by $\operatorname{Ross}^{16}$ in 1967, the pulmonary autograft has become an important therapeutic option for patients with severe aortic valve disease. In the young adult population, the pulmonary autograft has proven to be a practical alternative to prosthetic aortic valve replacement, with reported freedom from reoperation of $75 \%$ at 10 years ${ }^{17}$ on the autograft. However, additional procedures are necessary to address subsequent right ventricle-pulmonary conduit dysfunction. A major drawback of the Ross procedure is that the patient is converted from single-valve disease to iatrogenic 2-valve disease.

Surgical repair of the congenitally bicuspid aortic valve is an attractive alternative to valve replacement. Valve repair preserves the native aortic root and, therefore, enables normal annular growth to occur. This is an important consideration in the younger child whose aortic annulus will not accommodate an adult-sized prosthesis. The goal of aortic valve repair in these patients is to prevent secondary changes in left ventricular geometry and function and to facilitate sufficient annular growth to accommodate an aortic valve prosthesis when necessary. Furthermore, aortic valve repair preserves the pulmonary valve and does not preclude a subsequent pulmonary autograft. ${ }^{18}$ Conversely, the results of bicuspid aortic valve repair in children are frequently not encouraging, with some groups reporting that approximately $50 \%$ of patients will require valve replacement or exhibit significant valve dysfunction within 2 years. ${ }^{9}$

Several surgical techniques involving valve reconstruction with autologous tissue have been developed since Senning's initial report ${ }^{19}$ on the use of fascia lata to reconstruct the aortic valve in 1967. Although some authors discourage the use of cusp extension for aortic insufficiency in children,${ }^{20}$ experience with autologous pericardial cusp extension techniques for rheumatic aortic valve repair has demonstrated reasonable midterm durability in both adults and children. ${ }^{21-23}$ Early $^{24}$ and midterm ${ }^{21}$ results of cusp extension techniques to address bicuspid valve dysfunction are also encouraging. Using univariate analysis, van Son and colleagues ${ }^{9}$ identified the presence of a bicuspid aortic valve as an independent risk factor for early repair failure. When compared with cusp extension for bicuspid aortic valve disease, valve repair involving tricuspidization with cusp extension (TCE) appears to offer improved durability, albeit not statistically significantly so. ${ }^{21}$

Surgical repair of the bicuspid aortic valve must frequently address both residual stenosis and insufficiency, which may or may not be related to prior balloon dilation. We believe that it is critical not only to increase the cusp zone of apposition but also to establish tricuspid geometry to provide an optimal effective orifice area. Balloon valvuloplasty during childhood tends to disrupt valves along planes of least resistance, causing damage to delicate cusp tissue, which leads to valvular insufficiency. ${ }^{25}$ Balloon valvuloplasty had been performed in only
$24 \%$ of patients eligible for TCE in this series, whereas $64 \%$ of patients who were not TCE candidates had undergone previous balloon valvuloplasty. It may be beneficial to consider surgical valvotomy, rather than balloon valvuloplasty, in infants with critical bicuspid aortic stenosis and an adequate aortic annulus.

Before the introduction of the Ross procedure, the surgical strategy for congenital aortic valve disease at The Royal Children's Hospital was to delay valve replacement by performing palliative valve repairs until an adult-sized mechanical prosthesis could be used. ${ }^{26}$ The cusp extension technique for bicuspid aortic insufficiency was introduced in our unit at the same time as the Ross procedure. From 1996 to 1999, we performed cusp extensions, preserving bicuspid anatomy. The results in these early patients were disappointing, with excessive residual gradients and early failure owing to recurrent regurgitation (Appendix Figure 1). The technique of TCE was introduced in 1999. It is derived from valve tricuspidization, as promoted by Tolan and associates, ${ }^{27}$ and cusp extension, first described by Senning. ${ }^{19}$

The morbidity in our series of the Ross procedure is important, and this should be an argument in favor of continuing exploration of the valve repair techniques, but the autograft valve function at the term of follow-up is excellent. Only 2 patients had autograft failure, 1 of whom required reoperation. The stable performance of the autograft in this study compares very favorably with other series reported in the recent literature, ${ }^{5,28}$ where the rate of reoperation on the autograft is superior to the rate of reoperation on the right ventricular outflow tract. In our series, this may reflect the patient selection and the use of aortic valve repair in patients who are poor candidates for the Ross procedure. The predominant preoperative disease was pure aortic regurgitation in the TCE group $(P$ $=.023)$, whereas the Ross group predominantly had combined regurgitation and stenosis $(P=.044)$, with a tendency toward smaller annuli (range -4.4 to +8.7 versus -0.3 to +9 ). Although there was no statistically significant increase in autograft regurgitation over the time of follow-up, we did observe a slight increase in the mean regurgitation score in the Ross patients.

Over the time of the follow-up, the two groups had comparable reoperation rates; however, it is clear that aortic valve function in TCE patients is less stable than in Ross patients. Identification of risk factors contributing to TCE failure would clearly be beneficial for future patient selection, but we failed to detect any significant factors. The fact that we were unable to identify risk factors for TCE or Ross failure may suggest that our choice of procedure at the time of surgery was appropriate or that the power of the study is limited owing to the small number of events and/or patients. Patients at risk for failure with one procedure were directed toward the alternate procedure. Although not statistically significant, younger age at time of operation was associated with subsequent development of aortic insufficiency in TCE 
patients. This is disappointing inasmuch as limiting TCE to older patients defeats the primary benefit of valve repair in children, which is to delay valve replacement as long as possible.

Although early valve function after TCE is excellent, the results from this series and others ${ }^{21,29}$ suggest that long-term follow-up will be associated with an increased rate of reoperation. The importance of the characteristics of the material used for cusp extension in the long-term result is obvious and, therefore, the selection of material is essential. We belong to a school that has extensively studied and promoted the use of glutaraldehyde-treated autologous pericardium. ${ }^{12,13,22,30,31} \mathrm{We}$ harvest the thinnest portion of the pericardium and carefully clear it of any scar tissue. We have reduced the duration of the treatment to 8 minutes. However, other materials have been used and advocated by other teams. Most centers now avoid using glutaraldehyde-treated bovine ${ }^{32}$ or equine pericardium. There is one case report describing the use of dye-mediated photooxidation bovine ${ }^{33}$ pericardium in this context without cusp extension but without follow-up. Kalangos and associates ${ }^{34}$ also report good midterm results with the use of untreated autologous pericardium for rheumatic aortic valve repair. Similar reports by Grinda and colleagues ${ }^{23}$ and others ${ }^{22}$ with large series yield good midterm results as well for the cusp extension with glutaraldehyde-treated pericardium. Although thin expanded polytetrafluoroethylene appears to provide satisfactory function during early follow-up in the pulmonary position, this material is likely to tear at systemic pressure and its use in the systemic circulation has not been reported. In this context, and although the results are imperfect, there is no strong argument to justify for us a switch to an alternative material. Most teams involved with this operation would agree that the ideal material for aortic valve repair is still to be found.

The TCE is particularly well suited for the thickened cusps seen in pediatric patients with a history of valve stenosis or when significant secondary dysplasia contributes to increased valve gradient. However, it must be noted that other repair techniques exist for bicuspid aortic valve disease. In the setting of a bicuspid valve with thin cusps, symmetrical commissures without raphe and elongation of one free edge, triangular resection of the free edge without cusp extension is a very efficient repair technique. ${ }^{35,36}$ These patients often first present in the second or third decade and are rare in pediatrics settings.

\section{Limitations}

We recognize that this is a nonrandomized retrospective series. The patients are essentially different, because the two techniques address and are best suited for dissimilar valve anatomy. Therefore, the statistical comparison between the two groups should be interpreted carefully and more as an indication of the midterm performance of the TCE benchmarking with the Ross procedure.

\section{Conclusions}

This series demonstrates that TCE is a reliable palliation for symptomatic bicuspid aortic valve disease beyond infancy and is associated with very little morbidity. TCE should not be viewed as an alternative to the pulmonary autograft, which has very good midterm results. When integrated into a comprehensive surgical strategy, TCE may delay the timing of the Ross procedure or other aortic valve replacement while preserving ventricular function, especially in patients less suited for pulmonary autograft.

\section{References}

1. Basso C, Boschello M, Perrone C, Mecenero A, Cera A, Bicego D, et al. An echocardiographic survey of primary school children for bicuspid aortic valve. Am J Cardiol. 2004;93:661-3.

2. Elkins RC, Knott-Craig CJ, Ward KE, Lane MM. The Ross operation in children: 10-year experience. Ann Thorac Surg. 1998;65:496-502.

3. Luciani GB, Favaro A, Casali G, Santini F, Mazzucco A. Ross operation in the young: a ten-year experience. Ann Thorac Surg. 2005;80:2271-7.

4. Takkenberg JJM, Kappetein AP, van Herwerden LA, Witsenburg M, Osch-Gevers LV, Bogers AJJC. Pediatric autograft aortic root replacement: a prospective follow-up study. Ann Thorac Surg. 2005;80:1628-33.

5. Hazekamp MG, Grotenhuis HB, Schoof PH, Rijlaarsdam ME, Ottenkamp J, Dion RA. Results of the Ross operation in a pediatric population. Eur J Cardiothorac Surg. 2005;27:975-9.

6. Durham LA III, desJardins SE, Mosca RS, Bove EL. Ross procedure with aortic root tailoring for aortic valve replacement in the pediatric population. Ann Thorac Surg. 1997;64:482-6.

7. Laudito A, Brook MM, Suleman S, Bleiweis MS, Thompson LD, Hanley FL, et al. The Ross procedure in children and young adults: a word of caution. J Thorac Cardiovasc Surg. 2001;122:147-53.

8. David TE, Omran A, Ivanov J, Armstrong S, de Sa MP, Sonnenberg $\mathrm{B}$, et al. Dilation of the pulmonary autograft after the Ross procedure. J Thorac Cardiovasc Surg. 2000;119:210-20.

9. van Son JA, Reddy VM, Black MD, Rajasinghe H, Haas GS, Hanley FL. Morphologic determinants favoring surgical aortic valvuloplasty versus pulmonary autograft aortic valve replacement in children J Thorac Cardiovasc Surg. 1996;111:1149-56.

10. Rowlatt UF, Rimoldi HJ, Lev M. The quantitative anatomy of the normal child's heart. Pediatr Clin North Am. 1963;10:499-588.

11. Kirklin JW, Barratt-Boyes BG. Anatomy, dimension and terminology. In: Kirklin JW, Barratt-Boyes BG, editors. Cardiac surgery. 2nd ed. London: Churchill Livingstone; 1993. p. 3-60.

12. Chachques JC, Vasseur B, Perier P, Balansa J, Chauvaud S, Carpentier A. A rapid method to stabilize biological materials for cardiovascular surgery. Ann New York Acad Sci. 1988;529:184-6.

13. Vincentelli A, Zegdi R, Prat A, Lajos P, Latremouille C, LeBret E, et al. Mechanical modifications to human pericardium after a brief immersion in 0.625\% glutaraldehyde. J Heart Valve Dis. 1998;7:24-9.

14. Latremouille CP, Vincentelli A, Zegdi R, D'Attellis N, Chachques JC, Lassau JP, et al. Autologous pericardial patch harvesting site for cardiac valve repair: anatomic and morphometric considerations. J Heart Valve Dis. 1998;7:19-23.

15. Frater RWM. Aortic valve insufficiency due to aortic dilatation: correction by sinus rim adjustment. Circulation. 1986;74(3 Pt 2):I136-42.

16. Ross DN. Replacement of aortic and mitral valves with a pulmonary autograft. Lancet. 1967;2(7523):956-8.

17. Kouchoukos NT, Masetti P, Nickerson NJ, Castner CF, Shannon WD, Davila-Roman VG. The Ross procedure: long-term clinical and echocardiographic follow-up. Ann Thorac Surg. 2004;78:773-81.

18. Sakaguchi H, Elkins RC, Lane MM, McCue C. Effect of prior aortic valve intervention on results of the Ross operation. J Heart Valve Dis. 2003; $12: 423-9$

19. Senning A. Fascia lata replacement of aortic valves. J Thorac Cardiovasc Surg. 1967;54:465-70.

20. Haydar HS, He GW, Hovaguimian H, McIrvin DM, King DH, Starr A Valve repair for aortic insufficiency: surgical classification and techniques. Eur J Cardiothorac Surg. 1997;11:258-65. 
21. Odim J, Laks H, Allada V, Child J, Wilson S, Gjertson D. Results of aortic valve-sparing and restoration with autologous pericardial leaflet extensions in congenital heart disease. Ann Thorac Surg. 2005;80:647-54.

22. Tapia M, Brizard C, Fremont D, Luxereau P, Delarrat M, Deloche A, et al. [Conservative surgery in rheumatic aortic insufficiency]. Arch Mal Coeur. 1997;90:1611-4.

23. Grinda JM, Latremouille C, Berrebi AJ, Zegdi R, Chauvaud S, Carpentier AF, et al. Aortic cusp extension valvuloplasty for rheumatic aortic valve disease: midterm results. Ann Thorac Surg. 2002;74:438-43.

24. Doss M, Moid R, Wood JP, Miskovic A, Martens S, Moritz A. Pericardial patch augmentation for reconstruction of incompetent bicuspid aortic valves. Ann Thorac Surg. 2005;80:304-7.

25. Hawkins JA, Minich LL, Shaddy RE, Tani LY, Orsmond GS, Sturtevant JE, et al. Aortic valve repair and replacement after balloon aortic valvuloplasty in children. Ann Thorac Surg. 1996;61:1355-8.

26. Karl TR, Sano S, Brawn WJ, Mee RB. Critical aortic stenosis in the first month of life: surgical results in 26 infants. Ann Thorac Surg. 1990;50:105-9.

27. Tolan MJ, Daubeney PE, Slavik Z, Keeton BR, Salmon AP, Monro JL. Aortic valve repair of congenital stenosis with bovine pericardium. Ann Thorac Surg. 1997;63:465-9.

28. Pasquali SK, Cohen MS, Wernovsky G, Shera D, Spray TL, Marino BS. The relationship between neo-aortic root dilation, insufficiency and reintervention following the Ross Procedure in children and young adults. Circulation. 2005;112(Suppl II):presentation 1819 [abstract].

29. Alsoufi B, Karamlou T, Bradley T, Williams WG, Van Arsdell GS, Coles JG, et al. Short and midterm results of aortic valve cusp extension in the treatment of children with congenital aortic valve disease. Ann Thorac Surg. 2006;82:1292-300.

30. Chauvaud S, Jebara V, Chachques JC, el Asmar B, Mihaileanu S, Perier $\mathrm{P}$, et al. Valve extension with glutaraldehyde-preserved autologous pericardium: results in mitral valve repair. J Thorac Cardiovasc Surg. 1991;102:171-7.

31. Acar C, de Ibarra JS, Lansac E. Anterior leaflet augmentation with autologous pericardium for mitral repair in rheumatic valve insufficiency. J Heart Valve Dis. 2004;3:741-6.

32. Al-Halees Z, Gomciza B, Duran CM. Aortic valve repair with autologous pericardium. Ann Thorac Surg. 1998;65:601-2.

33. Kalangos A, Beghetti M, Christenson JT. Tricuspidalization of a bicuspid aortic valve with severe aortic valve insufficiency. $J$ Thorac Cardiovasc Surg. 2003;125:964-6.

34. Kalangos A, Beghetti M, Baldovinos A, Vala D, Bichel T, Mermillod $\mathrm{B}$, et al. Aortic valve repair by cusp extension with the use of fresh autologous pericardium in children with rheumatic aortic insufficiency. J Thorac Cardiovasc Surg. 1999;118:225-36.

35. Carpentier A. Cardiac valve surgery-the "French correction." J Thorac Cardiovasc Surg. 1983;86:323-37.

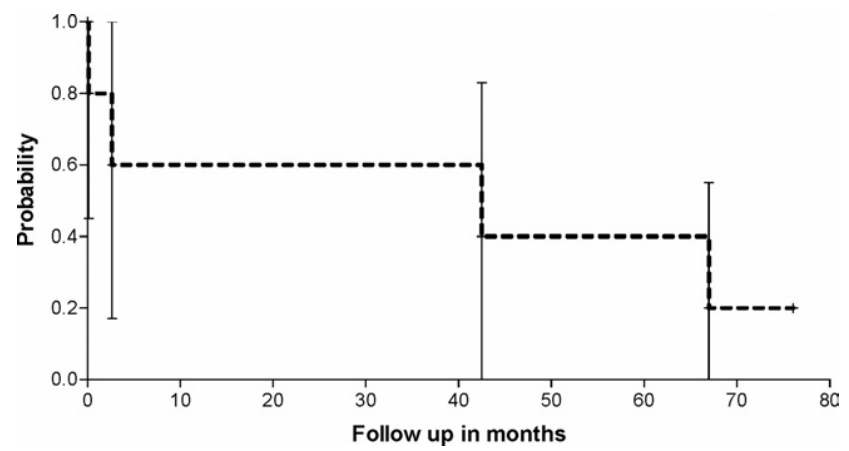

Appendix Figure 1. Actuarial freedom from reoperation for aortic valve repair for bicuspid aortic valve (Royal Children's Hospital, 1996-1998) with preservation of the bicuspid physiology. $N=5$. The only patient of the 5 with a long-term satisfactory result has not had a cusp extension with pericardium. The other 4 had cusp extension.
36. Casselman FP, Gillinov AM, Akhrass R, Kasirajan V, Blackstone EH, Cosgrove DM. Intermediate-term durability of bicuspid aortic valve repair for prolapsing leaflet. Eur J Cardiothorac Surg. 1999;15:302-8.

\section{Discussion}

Dr Glen Van Arsdell (Toronto, Ontario, Canada). Dr Caldarone, my partner, was the invited commentator. He was unable to be here. I am providing what are essentially his comments.

This is an impressive report describing TCE for bicuspid aortic valves compared with the Ross procedure. The results have been analyzed with an appropriate degree of caution, recognizing the variable nature of outcomes with leaflet extension.

The hallmark of a good operation is one that is easily reproduced and produces consistent results. In this respect, I think that at the Hospital for Sick Children we are still in a development phase with the leaflet extension technique. We have some difficulty verbalizing why some valves simply do not appear to be repairable. We know them when we see them, but cannot always say why. And when we do repair a valve, we have difficulty determining what technical details lead some to develop progressive insufficiency while others do not.

The solution for this dilemma is the development of a finer vocabulary describing the anatomy of the valve disease and better description of the components of the procedure performed. With a better vocabulary we can develop more consistency in our techniques and move the leaflet extension technique from an artistic operation to a more consistent, reproducible, and durable procedure.

Along the lines of better description of the problems, my questions are as follows:

The bicuspid aortic valve represents a spectrum of development from a well-developed but fused commissure to a nearly absent rudimentary raphe. One would anticipate better results with tricuspidization in the presence of a well-developed but fused commissure. Are you able to comment on the degree of development of the fused commissure and the impact that this had on your intraoperative decision-making, as well as the durability of the subsequent repair?

Dr McMullan. All the patients in this study had a bicuspid valve with a well-developed raphe. We believe that a well-developed raphe is necessary for this type of repair because it implies the presence of three coronary sinuses; we think that this type of valve should benefit from returning to a three-cusp type of physiology.

Dr Van Arsdell. So is it fair to infer that if it is really a true bicuspid valve with almost no hint of autotricuspidization, you recommend a Ross operation?

Dr McMullan. Yes, we would perform a Ross operation or perhaps a different type of repair.

Dr Van Arsdell. A large proportion of your patients had undergone balloon aortic valvuloplasty before their surgical procedure. Typically this results in tearing of the leaflet rather than the commissure. The tear tends to extend to the base of the cusp. Does the morphology of the tear dictate the choice between a Ross and a leaflet extension technique? Furthermore, do all torn leaflets require leaflet extension or can they be repaired by other published techniques?

Dr McMullan. The selection criteria for repair, as outlined in the talk, indicate that any involvement of the hinge point, the lowest portion of the valve leaflet, would preclude repair. The idea 
is to avoid a suture line that limits valve mobility. A larger percentage of patients in the Ross group had balloon dilation. Therefore, according to our selection criteria, they underwent a Ross procedure.

Dr Van Arsdell. If I am understanding your answer correctly, you really would not construct something where the predominant proportion of the leaflet is derived from pericardial tissue; is that correct?

Dr McMullan. That is correct. Two patients required extensive leaflet replacement early in the study. Those patients experienced early failure.

Dr Van Arsdell. Finally, I think that the problems we face are that some of the valves we want to repair are mixed lesions and frequently these involve patients who had previous aortic stenosis issues. The question is, a priori, before the operation, are you able to decide, based on echocardiographic criteria and your preoperative evaluation, with some degree of probability (ie, gradients or characteristics of mobility in the leaflet), which patients on a probability basis are going to need a Ross operation versus those that would need a repair?

Dr McMullan. This is an important question. We feel believe the outcome of both procedures should improve with the appropriate selection of patients. According to our selection criteria, a patient with pure aortic insufficiency or a large annulus would be more suitable for repair, whereas patients with a negative $z$-value for the annulus should receive a Ross-Konno procedure. Because our decision to perform one procedure over another was based on several factors, it is difficult to say whether any single factor would significantly affect the outcome of these procedures. This was not a randomized study; it is likely that we directed patients who were at higher risk for a Ross toward valve repair, and vice versa. Consequently, multivariate analysis of potential risk factors did not identify any factors that contributed to early failure. This supports the appropriateness of our selection criteria.

Dr Van Arsdell. I would say, based on reading your manuscript and listening to your presentation, that you have less residual stenosis than we do. This implies that we are making a different intraoperative decision to repair valves that are going to have a net less orifice. Perhaps we are being more aggressive about the raphe than you are. I'm not sure that this is the right decision. We need to begin to grapple with that and figure out which patients are best served.

Dr Bahaaldin Alsoufi (Toronto, Ontario, Canada). Obviously when you repair the valve, you try to make it function as close to normal as possible. In reality, you do not leave the operating room with a normal valve and often you have some residual defects, either stenosis or regurgitation. To further correct residual regurgitation, you may cause worsening stenosis. Those residual lesions will progress with time and may contribute to late repair failure. How do you manage those patients with residual lesions? How much gradient do you accept, or how much regurgitation on postrepair transesophageal echocardiogram will you accept before you decide to reinstitute cardiopulmonary bypass for either revision of the repair or replacement of the aortic valve?

Dr McMullan. As Dr Van Arsdell alluded, this is a custom procedure. It has not been standardized and much of the decisionmaking is based on the surgeon's personal experience and his comfort level with the amount of residual insufficiency after repair.

In general, if we found more than mild insufficiency after repair, we would either revise the repair or proceed to a Ross. In fact, the 2 patients who required early revision were found to have moderate insufficiency afte the initial repair. We elected to revise the repair at that time. In general, we do not attempt valve repair unless we are very confident that we will achieve a satisfactory result so that we avoid a situation in which we must replace a valve after unsuccessful repair.

Dr John W. Brown (Indianapolis, Ind). I have two questions. First, did age of the patient factor into which route you took? You tried to do a repair on the smaller children to try to let the annulus grow so you could come back and do a Ross; did that play a role? I did not get that from your presentation.

Dr McMullan. Age did not factor into our decision-making. Multivariate analysis of several factors, including age, failed to identify specific risk factors for failure. However, our decision to perform either procedure was biased by our stated selection criteria. Perhaps something like age would be identified as a risk factor for one procedure or the other in a randomized study.

Dr Brown. Second, although the Ross registry is not a perfect judge of how durable the Ross operation is, there are over 6000 patients in it, and the freedom from autograft excision is still $85 \%$ at 25 years. How do you think the repair technique is going to hold up? Your follow-up is at about 4 or 5 years at this point, and with 6 late failures, and, as you stated, it would seem that this is a palliative operation and probably is not going to compete with the Ross once you get out past 5, 6, or 7 years. Your comments.

Dr McMullan. I agree completely. The Ross is a very good procedure and, in appropriately selected patients, long-term results are very good. We are suggesting that this repair technique may be useful as an adjunct to the Ross procedure. By performing valve repair in patients who may be poorer candidates for the Ross procedure, we may avoid negative aspects of the Ross, including intrinsic weakness of the autograft, disruption of the right ventricular outflow tract, and converting 1-valve disease to 2-valve disease.

Certainly a large percentage of patients undergoing valve repair will ultimately move on to valve replacement. It is our hope that by initially performing valve repair, the patient can safely wait for a more permanent valve replacement later in life.

Dr Brown. What percentage of these patients do you think will have a good functioning aortic valve 10 to 15 years after the repair? Are you predicting $50 \%$ or $25 \%$ ?

Dr McMullan. I think we have shown that this technique of repair is a good palliative procedure but remains a palliation. 